\title{
Correction to: Thermal energy reduction in sanitary-ware industry by heat-recovering thermal engineering technologies
}

\author{
Carlos Cuviella-Suárez • \\ Antonio Colmenar-Santos · David Borge-Diez
}

Published online: 10 December 2021

(C) Springer Nature B.V. 2021

\section{Correction to: Energy Efficiency}

https://doi.org/10.1007/s12053-021-10005-w

The original version of the article unfortunately contained an error.

A data was inadvertently added in the third author's name David Borge-Diez. The correct author name is shown above.

The original article has been corrected.

Publisher's note Springer Nature remains neutral with regard to jurisdictional claims in published maps and institutional affiliations.

The original article can be found online at https://doi.org/ 10.1007/s12053-021-10005-w.

C. Cuviella-Suárez $(\bowtie) \cdot$ A. Colmenar-Santos

Control, Electronics and Electrical Engineering, UNED,

Juan del Rosal, 12 - Ciudad Universitaria, 28040 Madrid,

Spain

e-mail: carlos.cuviella@roca.net

A. Colmenar-Santos

e-mail: acolmenar@ieec.uned.es

D. Borge-Diez

Electrical Engineering and Automatic Systems, Campus de

Vegazana, S/N, University of León, 24071 León, Spain

e-mail: dbord@unileon.es 